\title{
SOBRE ALGUNOS CRITERIOS DE VERDAD NORMATIVA
}

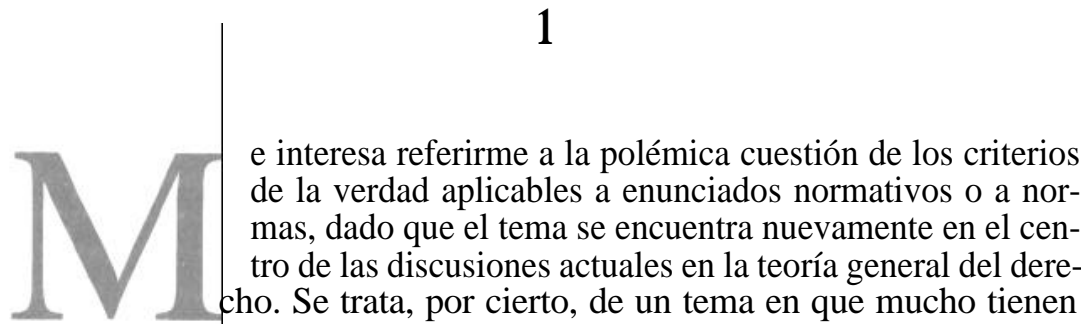
que decir moralistas y juristas, un tema por añadidura de muchas facetas y matices. Me limitaré, en consecuencia, a la discusión del problema en algún ensayista contemporáneo y en relación con la teoría jurídica. Ésta ha sustentado, en las últimas décadas, al reanudarse las preocupaciones por la estructura lógica del discurso normativo y por los criterios de verdad, opiniones dispares sobre el problema. Juristas dogmáticos y filósofos del derecho han reiterado que el lenguaje de la teoría del derecho, como todo discurso teórico, requiere de algunos criterios aceptados de consistencia y de algunos principios de compatibilidad deductiva. El conocimiento jurídico no sería conocimiento racional, con pretensión científica, de no lograr ese mínimo de respetabilidad lógica. Esta exigencia suele extenderse a la tesis más pretenciosa y más discutible de que el tema objeto del conocimiento científico del derecho -las normas positivas, por ejemplo, o el discurso jurídico global- esté también sujeto a condiciones más o menos rigurosas de consistencia y deductibilidad. Corresponde señalar que, frente a esta tendencia, han prosperado actitudes que no sólo reniegan acremente del carácter científico de la ciencia dogmática, cuyo uso ideológico suelen denunciar abundantemente, sino que repudian la idea misma de que el derecho (esto es: el conjunto de normas integrantes de un orden positivo) exhiba una estructura lógica que autorice a referirme a severas exigencias de consistencia o deductibilidad. Junto a un cierto escepticismo gnoseológico, que descarta la cientificidad de la jurisprudencia dogmática, tendríamos un irracionalismo normativo que hace de las normas datos brutos de una experiencia social; de ellas no tendría sentido predicar aquellas propiedades características que son condición necesaria para sostener luego la tesis de una lógica propia del discurso jurídico. Kelsen, que lejos de cuestionar los títulos científicos de la jurisprudencia dogmática, los toma como el punto de partida de la reflexión metateórica, es un exponente cabal de ese escepticismo frente a la racionalidad lógica de las normas mismas, las cuales no serían susceptibles de operaciones lógicas en sentido estricto. Una razón para sostener tal cosa, es destacar que las normas carecen de valores de verdad, no son ni verdaderas ni falsas, y, por ende, no son argumentos aceptables en un cálculo funcional veritativo. 


\section{2}

Sobre el punto vale la pena referirse a la evolución del pensamiento de G. von Wright; éste, cuya obra ha sido central en la investigación y desarrollo de los análisis lógicos del lenguaje normativo, considera actualmente que las normas, en su uso prescriptivo o regulativo, carecen de valor de verdad. Mal podrían, pues, ser variables en un cálculo lógico tradicional. En su uso corriente prescriptivo, las fórmulas deónticas desempeñarían una función importante en la determinación de las acciones, pero no expresarían proposiciones verdaderas o falsas. Por ende, carece de sentido hablar, en su respecto, de relaciones de contradicción o de deductibilidad. Con A. Ross, von Wright sostiene ahora que la normas no cuentan con una lógica y que, por lo tanto, el discurso normativo, en su uso práctico, es alógico ${ }^{1}$. Cabe hablar, sí, de la racionalidad de actividades, como la legislativa o la judicial, productoras de normas, pero sólo en algunos respectos y bajo ciertos criterios. Por su parte, los enunciados normativos, en una interpretación descriptiva o explicativa, expresan proposiciones verdaderas o falsas, sujetas a las leyes lógicas usuales.

Este irracionalismo normativo, como lo ha bautizado O. Weinberger ${ }^{2}$, es compartido por muchos lógicos contemporáneos, pero no alcanza necesariamente a otras propuestas lógicas -efectuadas en el terreno de sistemas lógicos divergentes o en extensiones de las lógicas clásicas- que aún Kelsen admite implícitamente; así, cuando normalmente se identifica la prohibición que una norma estatuye con la obligación de omisión de la misma conduc$\mathrm{ta}^{3}$. Lo que aquí me interesa es discutir la índole de las propiedades semánticas características -como la verdad- que quepa atribuir o descartar cuando hablamos de normas. Es frecuente -así en el autor que discutiré a continuación ${ }^{4}$ - sostener que la propiedad característica propuesta como afín en el discurso normativo, a la verdad en el discurso declarativo, es la validez. El extender a esa característica los atributos de la verdad preposicional es un paso frecuentemente propuesto o insinuado. Pero el asunto tiene sus bemoles. Por de pronto, la empecinada oscuridad de la noción misma de validez, tal como es utilizada por la doctrina jurídica. El vocablo, como es notorio, es empleado con los más variados sentidos y connotaciones por moralistas y juristas; ni juristas ni moralistas han llegado a un mínimo consenso sobre los alcances que quepa atribuir a la palabreja. Lo cierto es que, co-

1 Cf. G. von Wright, «Norms, truth and logic», en Practical reason, B, Blackmwell, Oxford, 1982, § 11 .

2 O. Weinberger, «Kelsens These von der Unanwendbrkeit logischer Regeln auf Normen», en Die Reine Rechtslehre in wissenschaftlicher Diskussion: H. Kelsen Instut. Viena, 1982; y, «Logik, Wirklchleit und Positivität in der Reinen Rechtslehre», en Rechtsystem und Gesellchaftliche Basis bei Hans Kelsen, Rechtstheorie, Beiheft 5, Berlín, 1984.

3 Cf. H. Kelsen, Reine Rechtslehre. 2a, ed. F. Deuticke, Viena, 1969, § 16, p. 77.

4 J. Kalinowski, Le problème de la vérité en morale et en droit, ed. E. Vitte, Lyon, 1967, Cito, en general, por la traducción castellana, Editorial Universitaria de Buenos Aires, 1979. Cf. también del mismo autor su reciente contribución al volumen Problemas abiertos en la filosofía del derecho, Doxa I, 1984, Universidad de Alicante, p. 113 ss. 
mo «verdad» en muchos contextos, «validez» puede ser un término encomiástico y poco o nada más. La afirmación de que tal o cual norma, regla, ley o principio es válido sólo importa la implicatura conversacional de que quien lo formula o menciona, considera que el principio, ley o norma en cuestión es bueno por alguna razón y, por ende, que en su opinión es merecedor de respeto y acatamiento. En otras ocasiones, sostener que una norma es válida no significa sino que la norma es considerada parte integrante de un orden jurídico positivo, sin que ello implique pronunciamiento valorativo alguno. Honestamente cabe pensar que en el terreno de las ciencias jurídicas dogmáticas, no se dan posturas nítidas con respecto al uso del término discutido. Por lo común, la tesis que equipara la validez con la pertenencia a un sistema, conforme al criterio que sea, considera esa propiedad razón suficiente para que se admita, expresa o calladamente, que la norma en cuestión deba ser aplicada. En otros términos, frente a nociones predominantemente descriptivas de la validez (esto es: más o menos susceptibles de algún tipo de verificación o falsificación empíricas), cunden las versiones en que el concepto exhibe un alcance prescriptivo.

Una tesis frecuente, como se ha apuntado, es la que relaciona la validez con la verdad. Así, por ejemplo, J. Kalinowski, para el cual la validez, en su tenor prescriptivo (las normas tienen «valor de validez... en cuanto obligan y se les debe obediencia») ${ }^{5}$, señala expresamente que «las normas valen cuando son verdaderas». Se trata, pues, de una tesis más fuerte; ya no se afirma que la validez tenga analogía, a los efectos de un cálculo, con la verdad, sino que la validez de una norma tiene como condición necesaria la postulada verdad de la misma. De aceptarse pareja tesis, es claro que importa a la teoría del derecho dirimir previamente la cuestión de la verdad de las normas jurídicas. Por de pronto, puede comprobarse que, dado que contamos con diversos conceptos de verdad, poco se gana con una discusión en términos generales, donde la multiplicidad de sentidos en juego hacen de la discusión un inútil espejismo. De ahí que me limitaré a los desarrollos sobre el punto de J. Kalinowski, quien no sólo afirma que las normas jurídicas positivas son verdaderas (en algún sentido), sino que polemiza con quienes difieren con ese punto de vista. Es cosa que va de suyo que las tesis referentes a la verdad de las normas jurídicas están ligadas a diversas tesis de tipo religioso (como es el caso explícitamente en Kalinowski) y filosófico. Pretendo eliminar los argumentos en favor de la verdad de las normas jurídicas que aduce el autor indicado, sin entrar en una discusión, acaso inútil, de las creencias metafísicas y religiosas que aduce. Considero que el recurso a tales tesis no constituye argumento filosófico suficiente para tener por acreditada la tesis, que sí importa a la jurisprudencia dogmática, relativa a la verdad de las normas jurídicas positivas. Kalinowski distingue diversas clases de normas; incluso pretende ofrecer alguna clasificación de las proposiciones normativas. Salvo las expresiones directamente imperativas, que no 
admitirían corrientemente ser calificadas de verdaderas o falsas, aunque sí de adecuadas, convenientes, etc., nuestro autor considera que las otras normas que analiza -normas morales generales y particulares, normas de derecho natural y normas de derecho positivo- pueden ser verdaderas en algún sentido. Me interesa examinar su análisis en cuanto se refiere a normas producidas por un acto humano. Se trata de las normas jurídicas «en sentido restringido», que son normas 1) «promulgadas de una manera u otra por el hombre»; y, 2) relativas «a los actos propiamente sociales» ${ }^{6}$. La primera característica las diferencia de la ley eterna y de la ley natural que no han sido objeto de promulgación humana alguna; la segunda característica las distingue de normas que expresarían algo así como «el plan divino del gobierno del mundo», la «idea creadora que define la naturaleza universal», que no son fenómenos sociales. Esas normas jurídicas, humanamente promulgadas y relativas a actos sociales, determinan «lo justo particular», esto es, regulan concretamente la conducta real de seres humanos concretos en situaciones específicas. Son ellas, pareciera, las que interesan básicamente a los juristas.

\section{4}

Las normas jurídicas positivas, así definidas, cree Kalinowski que pueden ser verdaderas de dos maneras distintas. Primeramente, habría normas jurídicas positivas que son verdaderas en cuanto son derivación deductiva de la ley natural, pensada como un conjunto de normas y enunciados que pueden servir de premisas en una deducción. Si esas normas naturales fueran verdaderas y el procedimiento deductivo, correcto, la conclusión también guardará esa característica. Ello supone, fuera de que se eche mano de una lógica suficiente, que pueda efectivamente verificarse que esas normas naturales son verdaderas en algún sentido interesante: «desde luego -sostiene Kalinowski- que si las normas de la ley natural son verdaderas, las normas positivas humanas deducidas de ellas son igualmente verdaderas cuando su inferencia se conforma a las reglas lógicas correspondientes». Pero una consecuencia no menos derivable es que entonces esas normas jurídicas humanas ya no requieren de promulgación para ser válidas (dado que su verdad es condición suficiente de su validez, como se vio), con lo cual no dejan de satisfacer la definición misma que las demarca. En cuanto inferibles de la ley natural, «obligan -confirma nuestro autor- en razón de la fuerza obligatoria de la ley natural de la cual son conclusiones». ¿Qué tiene en común esas derivaciones de una ley natural con nuestras normas positivas definidas a partir del hecho de su promulgación humana? Kalinowski nos advierte, por acaso, que esas normas derivadas deductivamente del derecho natural, y que en principio identifica con normas jurídicas positivas, son de un carácter mixto: semi-natural, semi-positivo. Y aparece este ejemplo: la ley natural obliga a respetar la vida humana: el legislador, al promulgar las normas penales sobre esa acción, especifica la norma natural restringiendo su aplicación a un determinado grupo humano en algún territorio. Pero in- 
cluso aunque ese legislador -afirma Kainowski- «no se hubiese pronunciado sobre el homicidio, las personas a las cuales se extiende la fuerza obligatoria del código penal... estarían aún obligados a respetar la vida humana en razón de la ley natural». Cabe señalar, por de pronto, que la promulgación de una norma positiva no coincide con el proceso de especificación a que Kalinowski nos remite: el ejemplo que pone desvirtúa que su descripción sea correcta. Da la impresión de que para él la función del legislador humano se redujera a integrar una norma natural incompleta que sólo enuncia el carácter deóntico que debe asignarse a una clase de acciones; el legislador humano especificaría su alcance mediante la determinación de ámbitos personales y territoriales de validez previamente no precisadas. Pero entonces cabe sostener que esa labor no es una derivación deductiva en sentido estricto; la pretendida ley natural no es más que una norma incompleta, de imposible aplicación por carecer de referencias suficientes a actos sociales. Lo que es más grave, la norma a la que se arribaría por esa vía no constituiría una «norma humana jurídica», tal como el propio Kalinowski las define, por carecer de promulgación. Este argumento por lo tanto, mal puede servir para demostrar que las normas jurídicas positivas que interesan a los juristas son verdaderas, puesto que no son asimilables a los enunciados que Kalinowski alude.

\section{5}

Pero, ¿tiene algún asidero atendible la afirmación de que las normas de la ley natural -premisas necesarias para la inferencia de normas positivas humanas- son verdaderas? El punto gira alrededor de creencias religiosas y metafísicas de nuestro autor, que no hay razón filosófica alguna para admitir. Sin entrar en detalles, Kalinowski adhiere a tesis extremas de un realismo axiológico, para el cual los valores tienen existencia real objetiva; existen cosas o hechos valiosos que serían la contrapartida de los conceptos y los enunciados axiológicos. Cree además Kalinowski que de esos objetos tenemos una suerte de acceso intuitivo, aunque no sensorial. Las normas de la ley natural tendrían fundamento en ese dominio ontológico. En lo que aquí interesa, hay una tesis que concierne concretamente a la cuestión de la verdad de las normas del derecho natural. Una norma, considera Kalinowski, podría ser verdadera, en sentido tarskiano, en cuanto si 'todo hombre debe respetar la vida humana' (entre comillas) fuera el nombre de la norma que prescribe tal deber, la expresión -y me limito a transcribir el texto-: «La norma 'todo hombre debe respetar la vida humana', es verdadera si y sólo si todo hombre debe respetar la vida humana», sería una versión adecuada de un criterio semántico de verdad. Esta fórmula, sin embargo, es engañosa, aunque, como apunta su autor, pueda parecer «sintácticamente correcta y semánticamente significativa». En efecto, ¿es la expresión entre comillas el nombre (propio) de una norma? Si lo glosáramos, utilizando otros recursos descriptivos, la propuesta de nuestro autor ya no parecerá aceptable: «La expresión formada por las letras t, o, d, o, h, etc. es verdadera si y sólo si todo hombre debe respetar la vida humana»; o, «el artículo $\mathrm{N}$ es verdadero si y sólo si, etc.». Estas formulaciones ya no parecen ni sintácticamente bien formadas ni semánticamente significativas, como para 
tenerlas como una definición de la verdad de una norma. Pero, en rigor, a Kalinowski no le interesa un análisis de los criterios semánticos de verdad de una expresión normativa. Le interesa más bien postular que una norma del derecho natural es verdadera conforme a criterios de correspondencia. $\mathrm{La}$ verdad de las proposiciones morales primeras, resultaría de la comprobación de su evidencia, la cual podría ser empírica o analítica. La evidencia empírica requiere de una percepción sensorial del objeto, lo que no puede darse en relación con normas que para nuestro autor son proposiciones, esto es, objetos no empíricos. La evidencia analítica es definida por nuestro autor de la siguiente manera: «una proposición es analíticamente evidente si su conformidad con la realidad puede ser controlada por un análisis de las realidades designadas por sus términos». Esta definición, por cierto, es harto discutible: los principios lógicos difícilmente serían considerados analíticos bajo este enfoque, salvo postulando fantasmales realidades que los cuantificadores, las variables, etc., mencionarían. Pero, en rigor, Kalinowski, una página más adelante vuelve al tradicional (y también insuficiente) criterio kantiano de analiticidad: «los juicios analíticamente evidentes... son universales cuando su predicado contiene todas las notas que definen al sujeto o algunas de ellas...». La evidencia analítica kalinowskiana se alcanza por un acto de iluminación intuitiva, puesto que «los juicios evidentes... nunca son conclusiones». La evidencia intuitiva, por lo tanto, «sigue siendo el criterio supremo de la verdad» y para Kalinowski curiosamente, «no hay sino una (sic) definición de la verdad»?

Interesa, pues, destacar, que los enunciados del derecho natural son verdaderos por comprobarse en forma intuitiva su evidencia analítica. Pero aun admitiendo, a los fines de la discusión, las discutibles tesis reseñadas, cabe preguntarse si es posible alcanzar esa evidencia analítica con respecto de por lo menos una norma del derecho natural. Afirmar que la norma que prescribe a todo hombre el respeto de la vida humana es verdadera, significa que intuitivamente podríamos comprobar su evidencia analítica. ¿Contamos con acto intuitivo semejante? Kalinowski, en todo caso, admite que esa vigencia analítica de darse siempre, es insastifactoria: en efecto, según tesis teológicas que Kalinowski comparte y menciona, el conocimiento intuitivo analítico de la verdad estaría vedado al ser humano, quien sólo se aproximaría a él por una «participación misteriosa en el Ser, participación concedida por quien es la plenitud del Ser». Dado que, en todo caso, esa misteriosa participación es escasa, Kalinowski aduce otra tesis: ¿cómo saber que la norma de derecho natural mencionada, cuya verdad debería comprobarse en una intuición analítica que no poseemos suficientemente, es efectivamente verdadera? Ya que no somos ni dioses ni ángeles -sujetos cognocentes que sí tendrían conocimiento intuitivo de tal norma- sólo alcanzaríamos a comprobar la verdad de la norma de marras «en virtud de lo que el hombre sabe de la ley eterna». Pero, resulta que como Kalinowski resignadamente admite, «no es gran cosa lo que (el hombre) sabe» ${ }^{8}$ de esa ley eterna (que ex- 
presaría nada menos que el plan divino de gobierno del mundo); para el lector de Kalinowski es un misterio, entonces, entender cómo una modesta norma humana positiva sería verdadera, en cuanto lógicamente heredera de la verdad de una premisa normativa del derecho natural a través de una inferencia deductiva, cuando no es posible conocer esa verdad previa sino defectuosamente y por vía de una participación misteriosa con un Ser que tampoco podemos conocer cabalmente en ninguno de los sentidos usuales en las ciencias de la palabra «verdad». Ante este fracaso, Kalinowski echa mano de una retórica abstrusa e incomprensible: si bien nuestro conocimiento (que debería ser analítico e intuitivo) del derecho natural, no puede alcanzarse, dado que poco podemos saber intuitivamente de la ley eterna, por eso «incomprensiblemente en razón de la simplicidad divina», tendremos que «admitir (sic) que (ese derecho natural) es exacto (verdadero), en virtud de la perfección de Dios», característica ésta que tampoco podemos conocer intuitivamente. La perfección de Dios sería, pues, la razón de la verdad de las premisas normativas de los enunciados del derecho natural, que deductivamente proveen de verdad a las normas del código penal francés (que es el texto que nuestro autor hace remontar a tan elevado fundamento). La perfección de Dios consiste, literalmente, en una imposibilidad lógica: «Dios es a la vez el Ser y el Deber-Ser» (todo ello con mayúsculas cuya función no se advierte; pues, qué es un Deber-Ser con mayúsculas). Sea ello como fuere, si a Dios se le atribuye las características usuales que indican, ya no los teólogos, sino inclusive los catecismos, como el ser eterno, mucho sentido no tiene considerar que Dios es un Deber-Ser, aun con mayúsculas. A un ente eterno y perfecto no tiene sentido alguno identificarlo con un deberser. De ahí, si mal no recuerdo, que Heidegger tildara blasfemia pareja identificación, que difícilmente encontaríamos en los pensadores preferidos de Kalinowski -Aristóteles y Tomás de Aquino- que se habrían visto en figurillas para decir, en griego y latín, que Dios es un Deber-Ser.

Este desarrollo, en todo caso, no logra su propósito: si ciertas normas positivas son verdaderas por derivación deductiva de premisas constituidas por normas de derecho natural, tendríamos que poder establecer de algún modo la verdad de las premisas, pero ello al parecer, no es posible suficienmente. Sólo cabrá postular a lo sumo la verdad de tales normas en méritos a supuestos religiosos discutibles y que, en todo caso, son ajenos a los procedimientos metódicos de las ciencias. Además, al no coincidir las normas positivas que el jurista analiza con las expresiones que Kalinowski imagina derivadas de la ley natural, sea cual fuera la verdad o evidencia de esta legislación metafísica, su verdad es ajena e irrelevante para las normas que promulgue algún legislador terrestre menos exaltado, como los autores del código penal francés.

\section{6}

Kalinowski pretende también, un tanto ridículamente, que la norma que obliga a los automovilistas a circular por la derecha en Francia es también verdadera. Cabe pensar que, para nuestro autor, ello implica o supone que esa norma de tráfico es normalmente obligatoria. Pero me parece que habría que señalar aquí una consecuencia grave del crudo positivismo ideoló- 
gico que late en el iusnaturalismo religioso derivado del terrible principio formulado en la Epístola a los Romanos, que impide desde esas posturas la crítica normal del derecho positivo.

Pero veamos: la obligación de conducir por la derecha, esa norma pedestre, no es, señala Kalinowski, una «simple conclusión de la ley natural»; es decir, no se trata de una norma que exprese «un deber-ser» que puede considerarse verdadera por su «conformidad con la realidad del deber-ser eterno». No, esa modesta norma municipal tiene una verdad más mediocre. Por tener los caminos de Francia y del mundo dos sentidos posibles de tráfico contrarios y excluyentes, Dios (y Perogrullo) habría misteriosamente resuelto en su plan de gobierno del universo y en su traducción en una ley natural destinada al uso terrestre, que «es necesario circular por la derecha o por la izquierda». Esta (inútil) norma daría como complemento adecuado de la ley natural -que al parecer no trata de la circulación automovilística-, en cuanto es el resultado de un actividad que la ley natural sí impondría regular a las autoridades municipales; a saber, el derecho natural impondría el saber de reglamentar de alguna manera la circulación peligrosa. Pero la directiva que la ley natural expresa es obviamente vacua: es obligatorio circular por la izquierda o es obligatorio circular por la derecha (si esta dirección fuera por alguna razón, el único complemento direccional de ir por la izquierda). Continúa Kalinowski informándonos pintorescamente que, en Francia, el legislador (autorizado por el derecho natural) ha «observado», con gran perspicacia (me permito apuntar) que «de acuerdo con la ley natural se debía circular en Francia por la derecha o por la izquierda». Además, nos informa Kalinowski, el mentado funcionario ha realizado una curiosa «observación» complementaria: ha «observado que en Francia no había obligación categórica de circular por la izquierda».

El legislador galo, modelo sin duda del legislador nacional, según proclaman los juristas también galos, habría concluído, ni corto ni perezoso y con gran refinamiento lógico (Kalinowski insinúa que habría echado mano nada menos que del modus tollendo ponens) que «en Francia se debería circular por la derecha». El legislador inglés, por alguna oscura razón escondida en el plan divino de gobierno del universo, habría «observado» que en Inglaterra «no había obligación categórica de circular por la derecha», concluyendo luego que los ingleses quedaban sujetos a la obligación de circular por la izquierda, pese a lo incómodo que eso nos parezca a los meros no ingleses. Concluye Kalinowski: «los códigos de tránsito en las rutas inglesas y francesas son igualmente verdaderos porque son igualmente conformes con la ley natural». Estas molestas normas positivas son verdaderas, pero no por la comprobación intuitiva de su evidencia, sino en virtud de una inferencia deductiva. Cabe preguntarse ahora; ¿podría ser falso el código de tránsito francés cuando la norma de derecho natural de la que heredaría su verdad es vacua, ya que no excluye (para una concepción del universo que sólo admita como alternativas el circular por la derecha o por la izquierda) posibilidad alguna? Acaso si el legislador francés hubiera decidido que en las rutas de Francia se circulara por la izquierda, ¿habría incurrido en error, habría actuado en disconformidad con las normas naturales? Kalinowski llega a la tesis de la verdad de la norma que mantiene a los automovilistas a la derecha en los caminos franceses con el siguiente argumento: junto a la vacua 
norma del derecho natural, Kalinowski atribuye a su legislador una extraña comprobación: a saber, que en Francia no existe norma que obligue categóricamente a circular por la izquierda. Pero ¿qué comprobación es ésta? Claro que no se trata de la verificación empírica de que, acaso, los conductores de vehículos suelen conducir en Francia por la derecha, pues aunque esta tesis empírica fuera verdadera, la conclusión normativa que Kalinowski pretende obtener por silogismo disyuntivo no sería lógicamente admisible, no sólo porque implicaría incurrir en el clásico error que denunciara Hume, sino porque supondría que de una tautología normativa (que es el único enunciado deóntico en las premisas) se inferiría una norma tautológica (como la que prescribe circular por la derecha). Lo que Kalinowski afirma es una tesis distinta: su perspicaz legislador habría «observado» o «comprobado» la no existencia, en Francia, de una norma que estatuyera la obligación de circular por la izquierda. Pero si bien para Kalinowski los valores y los enunciados lingüísticos son objetos reales (en algún sentido seguramente no unívoco), las normas son proposiciones y éstas, definidas como un tipo de relaciones, no son datos empíricos. Por consiguiente, por más que el legislador francés aguzara la vista hasta quedar bizco, nada podría haber observado o comprobado empíricamente, pues no hay, cree nuestro autor, acceso prescriptivo alguno a esos extraños objetos que, en esta confusa concepción, serían las normas. Y para complicar aún más las cosas resulta que lo observado por el legislador francés sería sólo un hecho negativo (para darle un nombre) de que no hay algo que, de todas maneras, no puede darse en experiencia observable alguna. Lo que el legislador podría haber comprobado, en el sentido de estar al tanto o tener conocimiento, es que él, ni sus predecesores, no habían dictado norma alguna que obligara a circular por la izquierda, quedando en libertad, de ocurrírsele regular la circulación, de optar por cualquiera de las alternativas fácticas y normativas que considerara convenientes. Frente a esta indeterminación de los contenidos de la legislación a dictar, francamente no se advierte cómo puede sostener que la decisión en definitiva adoptada sea verdadera por su conformidad con una norma de derecho natural vacía. La verdad como correspondencia, criterio único al que recurre nuestro autor, no permite sustentar la tesis de que el código de la circulación en Francia sea verdadero en ningún sentido. Y hace sospechar que cuando se habla de la verdad de normas positivas no se quiere decir lo que Kalinowski pretende ${ }^{9}$. Supongamos que se retorne a una remota mentalidad mítica que no hemos dejado de añorar, en la que toda acción humana está determinada, en última instancia, por el temple favorable o desfavorable del tótem de la tribu. Sea éste, pongamos y para darle un nombre, el Gran Oso Primordial. Si una acción mía es acertada -como la de lograr una refutación conveniente de las tesis de Kalinowski- diré que he cumplido con la obligación que el Gran Oso Primordial me ha impuesto de escribir estas páginas. De resultar ellas insuficientes, diré, con gran rigor lógico, que el Gran Oso Primordial me obliga a creer las cosas que Kalinowski sostiene

9 Puede hablarse de verdad de normas en forma menos pretenciosa, pues no se requiere tener noticia alguna del divino gobierno del mundo, partiendo de un criterio de verdad como coherencia, cf. C. Alchourrón y E. Bulygin, Essays in Legal Theory in Honor K. Makkonen, Helsinki, 1983. 
con respecto a la verdad de las normas jurídicas. En algún momento de lucidez y de incredulidad frente al Gran Oso, observo que nadie está obligado a creer en mis argumentos. ¿Bastaría ello para suponer verdaderas las afirmaciones de Kalinowski? En ese pequeño universo tribal, el desfavor del Gran Oso en mi contra obligaría a creer, con Kalinowski, en la verdad del código de la circulación en Francia. Como ese universo es inepto para intentar una explicación suficiente del tema discutido, y como el Gran Oso Primordial no existe, mucho me temo que no haya razón alguna para compartir la tesis de Kalinowski sobre la verdad de las normas jurídicas positivas. 